Check for updates

Cite this: RSC Adv., 2017, 7, 27637

Received 8th March 2017 Accepted 16th May 2017

DOI: $10.1039 / \mathrm{c} 7 \mathrm{ra02846f}$

rsc.li/rsc-advances

\section{Synthesis and drug release profile of a dual- responsive poly(ethylene glycol) hydrogel nanocomposite $\uparrow$}

\author{
Ernandes Taveira Tenório-Neto, (DD *ab Diego de Souza Lima, ${ }^{a}$ \\ Marcos Rogério Guilherme, ${ }^{a}$ Michele Karoline Lima-Tenório, ab \\ Débora Botura Scariot, ${ }^{c}$ Celso Vataru Nakamura, ${ }^{c}$ Marcos Hiroiuqui Kunitał ${ }^{a}$ \\ and Adley Forti Rubira*a
}

\begin{abstract}
This work describes the synthesis, characterization and application of a $\mathrm{pH}$ - and magnetic-responsive PEG hydrogel (HG) nanocomposite as a platform for drug delivery. PEG was used to produce permanent hydrogels with improved biocompatibility. A specific cross-linking/copolymerization chemistry was used to construct hydrogels with a controlled network organization so as not to affect the PEG biocompatibility. The hydrogels were prepared using vinylated PEG together with DMAAm, acrylic acid, and iron oxide nanoparticles. The water affinity, morphology, drug release profile and cytotoxicity of the resulting materials were studied in depth. The designed hydrogels were shown to be materials of biological relevance and of great pharmacological potential as drug carriers in drug delivery.
\end{abstract}

\section{Introduction}

Multi-responsive polymeric devices are able respond reversibly to more than one external stimulus., ${ }^{\mathbf{1 , 2}}$ Materials with enhanced responsive behavior take advantage over those that show a single-responsive behavior. Patients can often have fever that can last days, stomach aches, nausea, vomiting, and constant diarrhea. For this clinical picture, single-responsive devices leave a great deal to be desired and fail to ensure an effective therapy of those who suffer from more than one symptom.

In order to address these drawbacks, several researches have proposed new strategies to produce devices whose characteristics could be safely adjusted to ensure a successful treatment. Targeted drug delivery systems promise improved therapy, since they can transport drug load enough into a certain tissue. Controlling the drug release using a polymer carrier with a known release profile, which allows diffusion mechanism to be analytically adjusted, is a means to provide safer therapies. Some examples of release systems are PEGylated liposomes, ${ }^{3}$

\footnotetext{
a Department of Chemistry, State University of Maringá, Av. Colombo, 5790, CEP 87020-900, Maringá, Paraná, Brazil. E-mail: tenorioernandes@gmail.com; afrubira@uem.br; Tel: +55 423220 3062; +55 4430113686

${ }^{b}$ Department of Chemistry, State University of Ponta Grossa, Av. Gen. Carlos Cavalvanti, 4748, CEP 84030-900, Ponta Grossa, Paraná, Brazil

'Department of Basic Sciences of Health, State University of Maringá, Av. Colombo, 5790, CEP 87020-900, Maringá, Paraná, Brazil

$\dagger$ Electronic supplementary information (ESI) available. See DOI: 10.1039/c7ra02846f

\$ In memoriam.
}

tablets of chitosan and cellulose acetate phthalate, ${ }^{4}$ PVP microspheres, ${ }^{5}$ and also hydrogels. ${ }^{6}$

Hydrogels (HGs) are polymers with three-dimensional network structure which are able to absorb a large amount of water and/or biological fluids. ${ }^{7,8}$ HGs have received considerable attention due to their ability to swell without being dissolved into solvent, which allows drugs/nutrients to be systematically diffused and this makes them very similar to natural tissues. This characteristic makes the HG important for a wide range of applications, including controlled release of drug, and tissue engineering. ${ }^{9}$ In addition, the possibility of using magnetic field, and/or pH stimuli to control the swelling of a hydrogel is considered to be highly advantageous for their future exploitation in the biomedical field. ${ }^{\mathbf{1 0}}$

Consistent hydrogels with great pharmacological potential can be obtained from poly(ethylene glycol) (PEG) which ensures improved biocompatibility. The PEG systems are among the most widely used in the biomedicine. PEG has been approved by the U.S. Food and Drug Administration (FDA) for a variety of clinical uses. ${ }^{11}$ It can be easily converted into a macromere (or cross-linking agent) by reacting its two hydroxyl-end groups with other reactive groups, such as methoxyl, carboxyl, amine, thiol, azide, vinyl sulfone, azide, acrylate, and so on. ${ }^{12}$

This work aimed at synthetizing a PEG-based hydrogel with a dual-responsive behavior ( $\mathrm{pH}$ - and magnetic-responsive) as a platform for drug delivery. Prednisolone was the drug model. A specific cross-linking/copolymerization chemistry was used to construct a permanent hydrogel so as not to compromise the PEG biocompatibility. PEG was vinyl-modified ( $\left.{ }^{\mathrm{GMA}} \mathrm{PEG}\right)$ with glycidyl methacrylate (GMA) to be converted into the hydrogel. 
The advantage of such an approach is that it allows the polymer network organization to be controlled. ${ }^{13}$ The enhancement of responsive behavior of $\mathrm{HG}$ was achieved by cross-linking GMAPEG with sodium acrylate (SA) and $N, N^{\prime}$-dimethyl acrylamide (DMAAm) in the presence of ultrasound-dispersed iron oxide nanoparticles. The drug release profile and the swelling capacity under magnetic field were studied to estimate the performance of the formed hydrogel.

\section{Experimental}

\subsection{Materials}

Poly(ethylene glycol) (PEG) $M_{\mathrm{n}}$ 950-1050 $\mathrm{g} \mathrm{mol}^{-1}$, glycidyl methacrylate (GMA), sodium persulfate $\left(\mathrm{Na}_{2} \mathrm{~S}_{2} \mathrm{O}_{8}\right), N, N^{\prime}$ dimethyl acrylamide (DMAAm), acrylic acid (AAc), iron(II, III) oxide nanopowder $\left(\mathrm{Fe}_{3} \mathrm{O}_{4}\right.$-average size of $\left.150 \mathrm{~nm}\right)$ and dimethyl sulfoxide (DMSO) were purchased from Sigma-Aldrich. Acetone and sodium hydroxide $(\mathrm{NaOH})$ in pellets were supplied by Fmaia. All chemicals were of analytical grades and used without further purification. MTT salt (3-(4,5-dimethylthiazol-2-yl)-2,5diphenyltetrazolium bromide) was purchased from Amresco®. Fetal bovine serum (FBS), DMEM (Dulbecco's Modified Eagle's Medium) and RPMI 1640 (Roswell Park Memorial Institute medium) were obtained from Gibco®.

\subsection{Preparation of sodium acrylate (SA) from acrylic acid (AAc)}

The hydrogel-forming solutions were prepared upon addition of AAc, in the acrylate salt form, in order to prevent overheating over gelation at $70{ }^{\circ} \mathrm{C}$ owing to exothermic reaction with $\mathrm{Na}_{2} \mathrm{~S}_{2} \mathrm{O}_{8}$ (initiator). In a common example of neutralization, 50 $\mathrm{mL}$ of AAc were added to acetone at room temperature while stirring. Next, $28.6 \mathrm{~g}(0.71 \mathrm{~mol})$ of $\mathrm{NaOH}$ were slowly added to the stirred solution. After $5 \mathrm{~h}$, the clear solution turned to a whitish suspension, owing to salt precipitation. The precipitate was filtered under vacuum and left to dry in a ventilated oven at $35^{\circ} \mathrm{C}$ for $48 \mathrm{~h}$.

\subsection{Synthesis of macromere based on GMA-modified PEG ( ${ }^{\text {GMA }}$ PEG)}

Before hydrogel synthesis, the poly(ethylene glycol) was modified with GMA to convert it into cross-linkable polymer. The experimental conditions for PEG modification as well as for hydrogel synthesis were performed according to our previous work. ${ }^{12}$ Briefly, $16 \mathrm{~g}$ of PEG $(16 \mathrm{mmol})$ were added to $80 \mathrm{~mL}$ of water at $50{ }^{\circ} \mathrm{C}$ while stirring. The $\mathrm{pH}$ of the mixture was adjusted to $\mathrm{pH} 10.5$ with addition of $\mathrm{NaOH}$ pellets. Afterwards, $4.8 \mathrm{~mL}$ of GMA (32.4 mmol) were introduced, causing a spontaneous decrease in $\mathrm{pH}$ to $c a$. 7. The solution of PEG with GMA was left to react for $6 \mathrm{~h}$ under mild stirring. This solution containing ${ }^{\mathrm{GMA}}$ PEG $\left(0.2 \mathrm{~g} \mathrm{~mL}^{-1}\right)$ was used for preparing the hydrogels.

\subsection{Synthesis of hydrogels based on ${ }^{\mathrm{GMA}}$ PEG}

PEG-based hydrogels were synthesized using a chemical approach that has been reported by Lima-Tenório et al. with some adaptations. ${ }^{14}$ Briefly, $5 \mathrm{~mL}$ of ${ }^{\mathrm{GMA}} \mathrm{PEG}$ solutions were
Table 1 Amounts of DMAAm, SA, and $\mathrm{Fe}_{3} \mathrm{O}_{4}$ used for gelation ${ }^{a}$

\begin{tabular}{llcl}
\hline Sample name & DMAAm $(\mathrm{g})$ & $\mathrm{SA}(\mathrm{g})$ & $\mathrm{Fe}_{3} \mathrm{O}_{4}(\mathrm{~g})$ \\
\hline $\mathrm{A} 1$ & 0.5 & 0.6 & - \\
$\mathrm{A} 1 \_1$ & 0.5 & 0.6 & 0.001 \\
$\mathrm{~A} 1 \_3$ & 0.5 & 0.6 & 0.003 \\
$\mathrm{~A} 2$ & 0.5 & 1.2 & - \\
$\mathrm{A} 2 \_1$ & 0.5 & 1.2 & 0.001 \\
$\mathrm{~A} 2 \_3$ & 0.5 & 1.2 & 0.003 \\
${ }^{a}$ volume of solvent: & $5 \mathrm{~mL}$ of ${ }^{\mathrm{GMA}} \mathrm{PEG}$ solution and $5 \mathrm{~mL}$ of distilled \\
water. & & & \\
& &
\end{tabular}

diluted with $5 \mathrm{~mL}$ of distilled water. Desired amounts of DMAAm, SA, and $\mathrm{Fe}_{3} \mathrm{O}_{4}$ were added to ${ }^{\mathrm{GMA}}$ PEG solution (Table 1). The as-prepared solution was subjected to ultrasonic irradiation with the use of a probe of ultrasonic oscillation (Cole Parmer® 500, model EW-04711-40) by applying a frequency of $20 \mathrm{kHz}$ for $3 \mathrm{~min}$ and an amplitude of $30 \%$ for $3 \mathrm{~min}$. Then, $0.03 \mathrm{~g}$ of $\mathrm{Na}_{2} \mathrm{~S}_{2} \mathrm{O}_{8}$ were added to stirred solution, which was kept under ultrasound until a stiff material (gelation) be formed. The thus obtained hydrogels was washed with distilled water and stored at $15{ }^{\circ} \mathrm{C}$ before swelling experiments.

\subsection{Swelling measurements}

Swelling kinetics of the hydrogels were investigated by immersing the $1 \mathrm{~cm}^{3}$ of known hydrogel mass into buffer solutions of $\mathrm{pH} 1.2,3.5,5$, and 7.4 , at $36.5{ }^{\circ} \mathrm{C}$ with or without magnetic field. The hydrogels were withdrawn from the buffer solutions, the excess water droplets on the surface were wiped off carefully, and the samples were weighed at each new timestep until to achieve the swelling equilibrium. The swelling measurements were repeated two times for checking the reproducibility. The relative mass of the hydrogels $\left(\mathrm{m} / \mathrm{m}_{0}\right)$ was obtained by relating $m$ which is the mass of the swollen hydrogel at certain time with the initial hydrogel mass $\left(m_{0}\right)$. The graphs were constructed by plotting the relative mass $\left(\mathrm{m} / \mathrm{m}_{0}\right)$ against time $(t)$.

\subsection{Release of prednisolone from hydrogels under magnetic field}

In this work, prednisolone was used as a drug model. Prior to gelation, prednisolone was introduced to the hydrogel-forming solution to be loaded during the hydrogel synthesis. The amount of prednisolone corresponded to $10 \%(\mathrm{w} / \mathrm{w})$ of the reactants used in the feed solutions. The approach to prepare prednisolone-loaded hydrogels was the same of Section 2.4.

A known weight of prednisolone-loaded hydrogel was added to a glass reactor containing $500 \mathrm{~mL}$ of either simulated gastric fluid ( $\mathrm{pH}$ 1.2) or simulated intestinal fluid ( $\mathrm{pH}$ 7.4). In order to avoid a gradient concentration, these solutions were homogenized with the use of a peristaltic pump (with flow of $60 \mathrm{~mL}$ $\mathrm{min}^{-1}$ ) which is coupled in a flow cuvette (pathlength of $1 \mathrm{~cm}$ ) (Fig. 1).

The absorption readings were done at the specified times by means of an UV-vis spectrophotometer (Thermo Scientific 


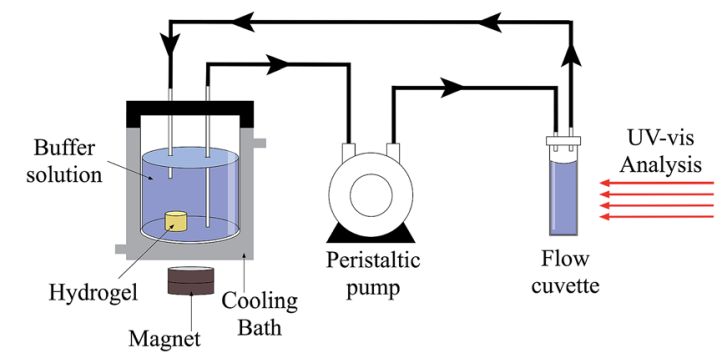

Fig. 1 Scheme illustrating the experimental apparatus used in the prednisolone release.

Genesys $^{\mathrm{TM}} 10 \mathrm{~s}$ ). The absorption readings were made at $242 \mathrm{~nm}$ or $247 \mathrm{~nm}$ which is the wavelength for the maximum absorption of prednisolone at pH 1.2 and $\mathrm{pH}$ 7.4, respectively. ${ }^{6,15}$

The concentration of prednisolone released from the hydrogels were determined from analytical curves (see ESI $\dagger$ ) which correlates the absorption to the concentration of prednisolone. The measures of release were performed applying a constant magnetic field of intensity 48 MGOe.

\section{Characterizations}

\subsection{Scanning electron microscopy (SEM)}

The hydrogels were swollen to equilibrium in buffer solutions of pH 1.2 or 7.4, prior to SEM imaging. They were withdrawn from water and immediately frozen by immersion in liquid nitrogen before being lyophilized for $24 \mathrm{~h}$. Under these conditions, it is supposed that the morphology of the swollen hydrogels is maintained. The samples were fractured and sputter-coated with a thin layer of gold and the SEM images were obtained in a scanning electron microscope (Shimadzu, model SS550 Superscan) by applying an acceleration voltage of $15 \mathrm{kV}$ and a current intensity of $30 \mu \mathrm{A}$.

\subsection{Fourier transform infrared spectroscopy (FTIR)}

The FTIR spectra were recorded in a Bruker spectrometer model Vertex-70V. Powdered samples were prepared into pellets with $\mathrm{KBr}$. The scan range varied from 400 to $4000 \mathrm{~cm}^{-1}$, and 128 scans were run for each spectrum to reach the resolution of 4 $\mathrm{cm}^{-1}$.

\subsection{Cytotoxicity measurement}

Normal kidney epithelial cells originated from African green monkey (VERO cells - ATCC@ CCL81) and human colorectal adenocarcinoma cell line HT-29 (ATCC® HTB-38 ${ }^{\mathrm{TM}}$ ) were maintained in DMEM, supplemented with 10\% FBS and incubated at $37{ }^{\circ} \mathrm{C}$ and $5 \% \mathrm{CO}_{2}$ tension, during 96 h. J774.A1 macrophages were maintained in RPMI 1640, pH 7.6, supplemented with $10 \% \mathrm{FBS}$ at $37{ }^{\circ} \mathrm{C}, 5 \% \mathrm{CO}_{2}$ atmosphere. The $5.0 \times$ $10^{5}$ macrophages, the $2.5 \times 10^{5}$ VERO and HT-29 cells were placed in 96-wells microplate after trypsinization. Cells adhered for $24 \mathrm{~h}$ and, next, different concentrations of the hydrogels were dispensed over the cells and the microplate was incubated at the same conditions described above. Cellular viability was determined after $72 \mathrm{~h}$ by using MTT method. Briefly, MTT solution in PBS was prepared at $2 \mathrm{mg} \mathrm{mL}^{-1}$ and $50 \mu \mathrm{L}$ were placed in each well. Microplates were incubated during $4 \mathrm{~h}$, in the absence of the light and, next, formazan crystals were soluble with DMSO. Purple color generated from mitochondrial enzymatic metabolism of viable cells was measured on spectrophotometer microplate reader, at $570 \mathrm{~nm}$ wavelength. In addition, neutral red method was also used to measure cell viability. Briefly, neutral red solution $\left(40 \mu \mathrm{g} \mathrm{mL}{ }^{-1}\right)$ was added in each well and incubated for $3 \mathrm{~h}$ at $37^{\circ} \mathrm{C}$. Next, fixing solution $\left(1 \% \mathrm{CaCl}_{2}\right.$ and $2 \%$ formaldehyde in $\left.\mathrm{PBS}\right)$ was added for less than $5 \mathrm{~min}$. The dye was solubilized with ethanol/water $50 \%$ and glacial acetic acid $1 \%$ and the cell viability was measured on spectrophotometer microplate reader, at $540 \mathrm{~nm}$ wavelength. $\mathrm{CC}_{50}$ index was calculated as the enough concentration to kill $50 \%$ of the cells when compared to negative control.

\section{Results and discussion}

\subsection{FTIR analysis}

Fig. 2 shows the FTIR spectra of ${ }^{\mathrm{GMA}} \mathrm{PEG}$, and A1_3 hydrogel in the spectral range of $2000 \mathrm{~cm}^{-1}$ to $400 \mathrm{~cm}^{-1}$. The spectra of ${ }^{\mathrm{GMA}}$ PEG showed characteristic signals of PEG and GMA. The bands at $1720 \mathrm{~cm}^{-1}$ and $1640 \mathrm{~cm}^{-1}$ in the spectra of ${ }^{\text {GMA }}$ PEG were attributed to stretching vibrations of carbonyl groups $(\nu \mathrm{C}=\mathrm{O})$ and vinyl groups $(\mathrm{C}=\mathrm{C})$, respectively. ${ }^{16,17}$ These signals correspond to conjugated esters derived from GMA moieties. In addition, bending vibrations corresponding to $=\mathrm{C}-\mathrm{H}$ was found at $840 \mathrm{~cm}^{-1}$. Furthermore, in the same spectrum, the bands at $910 \mathrm{~cm}^{-1}$ and $860 \mathrm{~cm}^{-1}$, owing to $\nu_{\text {as }} \mathrm{C}-\mathrm{C}$ and $\nu_{\mathrm{s}} \mathrm{C}-\mathrm{O}$ of the epoxy ring from GMA, respectively, were not observed, ${ }^{\mathbf{1 8}}$ indicating that PEG reacted with GMA by an epoxide ringopening mechanism.

The signal at $1620 \mathrm{~cm}^{-1}$, in the spectra of A1_3 hydrogel, corresponds to $>\mathrm{C}=\mathrm{O}$ asymmetric stretching vibration of carbonyl groups from both DMAAm and acrylate groups. ${ }^{\mathbf{1 9 , 2 0}}$ Moreover, the signal corresponding to $\nu_{\mathrm{s}} \mathrm{C}=\mathrm{O}$, owing to acrylate group, appeared at $1400 \mathrm{~cm}^{-1} \cdot{ }^{21}$ In the same spectra, the high

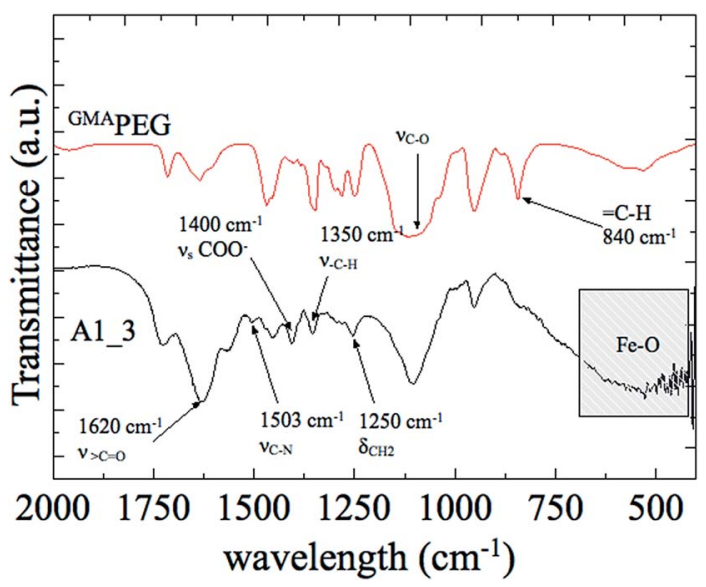

Fig. 2 FTIR spectra of GMAPEG and A1_3 hydrogel in the spectral range of $2000 \mathrm{~cm}^{-1}$ to $400 \mathrm{~cm}^{-1}$. 
intensity band at $c a .570 \mathrm{~cm}^{-1}$ is due to $\mathrm{Fe}-\mathrm{O}$ stretching vibrations $\mathrm{s}^{22}$ and the peaks at $1503 \mathrm{~cm}^{-1}$ and $1250 \mathrm{~cm}^{-1}$ results from $\nu_{\mathrm{C}-\mathrm{N}}$ and $\delta_{\mathrm{CH}_{2}}$, respectively.

\subsection{Hydrogel morphology}

Fig. 3 shows SEM micrographs of fractured A2_3 hydrogel (richer in $\mathrm{Fe}_{3} \mathrm{O}_{4}$ ) swollen at $\mathrm{pH} 1.2$ and 7.4 with and without magnetic field (MF). This approach gives relevant insight into effects of MF on the porous morphology which is known to have direct relation with water transport through the hydrogel. Porous morphology plays an important role in the drug diffusion because these structures allow the drug to move inwards and outwards the $3 \mathrm{D}$ polymer network. The porous hydrogels have been shown to be useful as a polymer carrier for drug delivery. SEM images showed that the hydrogels swollen to equilibrium in the same $\mathrm{pH}$ are porous with or without MF, suggesting that such morphology is related to macromolecular orientation, not to iron oxide particles. The influence of $\mathrm{pH}$ on porous morphology is related to ionizable groups, such as carboxylic groups $(-\mathrm{COOH})$, in the hydrogel network. These groups are present in SA and undergo ionization at higher $\mathrm{pH}$. The structural changes, which is the result from molecular interactions due to $\mathrm{pH}$ variations, affects the morphological properties, such as porosity, polymer density and so on. This reflects the alterations on SEM images of those hydrogels at different $\mathrm{pH}$.

In addition, it is important to highlight that at $\mathrm{pH} 7.4$ the porosity changed significantly when compared to those observed at $\mathrm{pH}$ 1.2, showing a relation between $\mathrm{pH}$ and porous morphology.

\subsection{Swelling measurements}

Swelling kinetics were performed to investigate the mechanisms that regulate water transport taking into account the effects of magnetic field and pH. Fig. 4 shows the water absorption kinetic of hydrogels swollen over a wide $\mathrm{pH}$ range with or without MF.

All hydrogel compositions were found to be $\mathrm{pH}$-responsive. The higher the $\mathrm{pH}$ of swelling, the greater the water absorption capacity of hydrogel. Also significant was the result that at pH 1.2 and 3.5 the $m / m_{0}$ ratio of all the samples decreased after they absorbed some amount of liquid. This behavior may be associated with two main factors: (i) erosion of the hydrogel network and/or (ii) increase in the cross-linking density owing to hydrogen bonds from carboxylic groups. The erosion is a result of either the burst of vesicular structure (due to high osmotic pressure during the swelling) or the degradation of polymer networks. It has been reported that ester groups from ${ }^{\mathrm{GMA}} \mathrm{PEG}$ structure may be cleaved, particularly in acid media, contributing to erosion mechanism. ${ }^{12}$

On the other hand, the presence of polyacrylic acid in the hydrogel network plays a predominant role on swelling profile. The $\mathrm{p} K_{\mathrm{a}}$ of polyacrylic acid is $c a .4 .5 .^{23}$ When the $\mathrm{pH}<\mathrm{p} K_{\mathrm{a}}$ the carboxylic groups are predominantly undissociated $(-\mathrm{COOH})$, providing strong intra- and inter-macromolecular interactions, such as hydrogen bonds that contribute to hydrophilicity reduction. ${ }^{24}$ Therefore, the water inside the hydrogel is ejected into external solution leading the $\mathrm{m} / \mathrm{m}_{0}$ ratio to an effective decrease. When the $\mathrm{pH}>\mathrm{p} K_{\mathrm{a}}$ the carboxylic groups are predominantly dissociated $\left(-\mathrm{COO}^{-}\right)$, generating electrostatic repulsion forces that extend the polymer chains and increase the contact with water. As a result, the hydrogel affinity for water increases.

The influence of the magnetic particles as well as the magnetic field on swelling behavior for samples containing iron oxide was also investigated. In absence of magnetic field, no changes in swelling profiles were observed (Fig. 4C and E). In fact, there was a discrete decrease in swelling equilibrium at $\mathrm{pH}$ 7.4 for A2_1 and A2_3, owing to nanoparticles acting as physical barriers against the water diffusion (called tortuosity effect). ${ }^{25}$ The tortuosity effect was also observed at acid $\mathrm{pH}$, where the

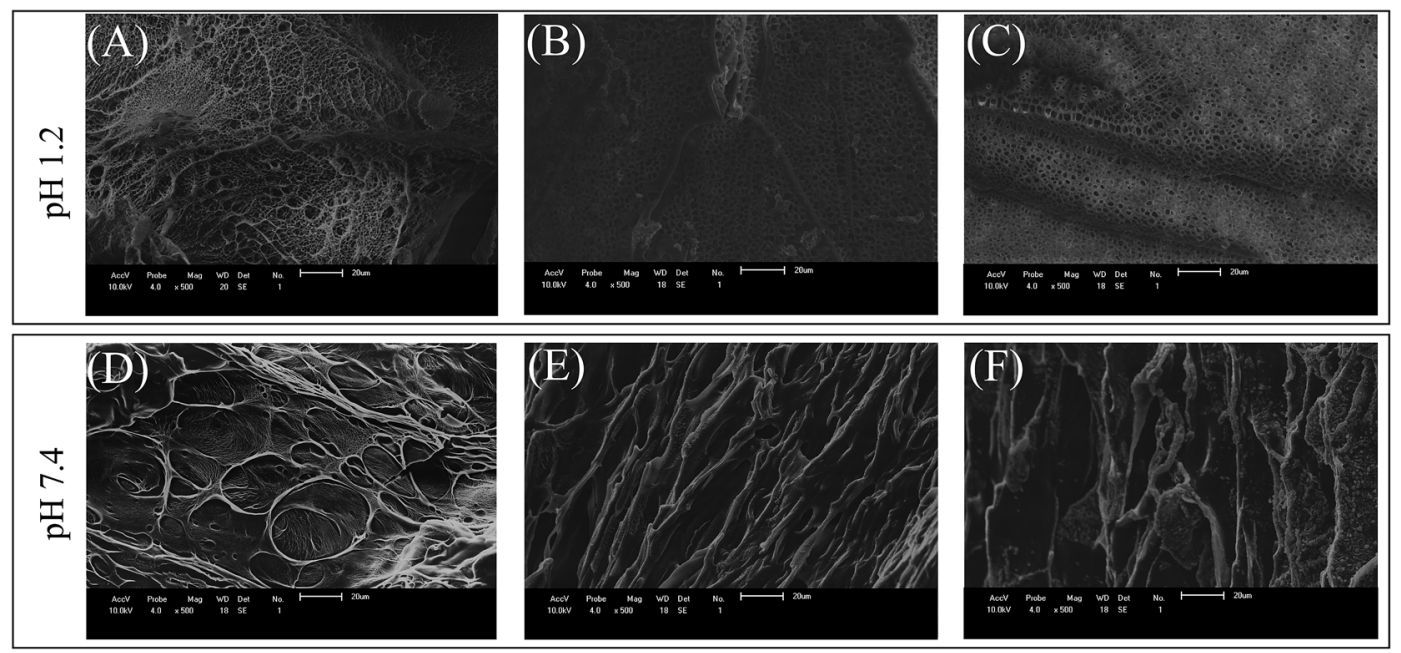

Fig. 3 SEM images of fractured frozen hydrogels after being swelled to equilibrium: at pH 1.2 (A) A2, (B) A2_3 with MF, (C) A2_3 without MF; at pH 7.4 (D) A2, (E) A2_3 with MF, (F) A2_3 without MF. Scale bars of images are $20 \mu \mathrm{m}$. 

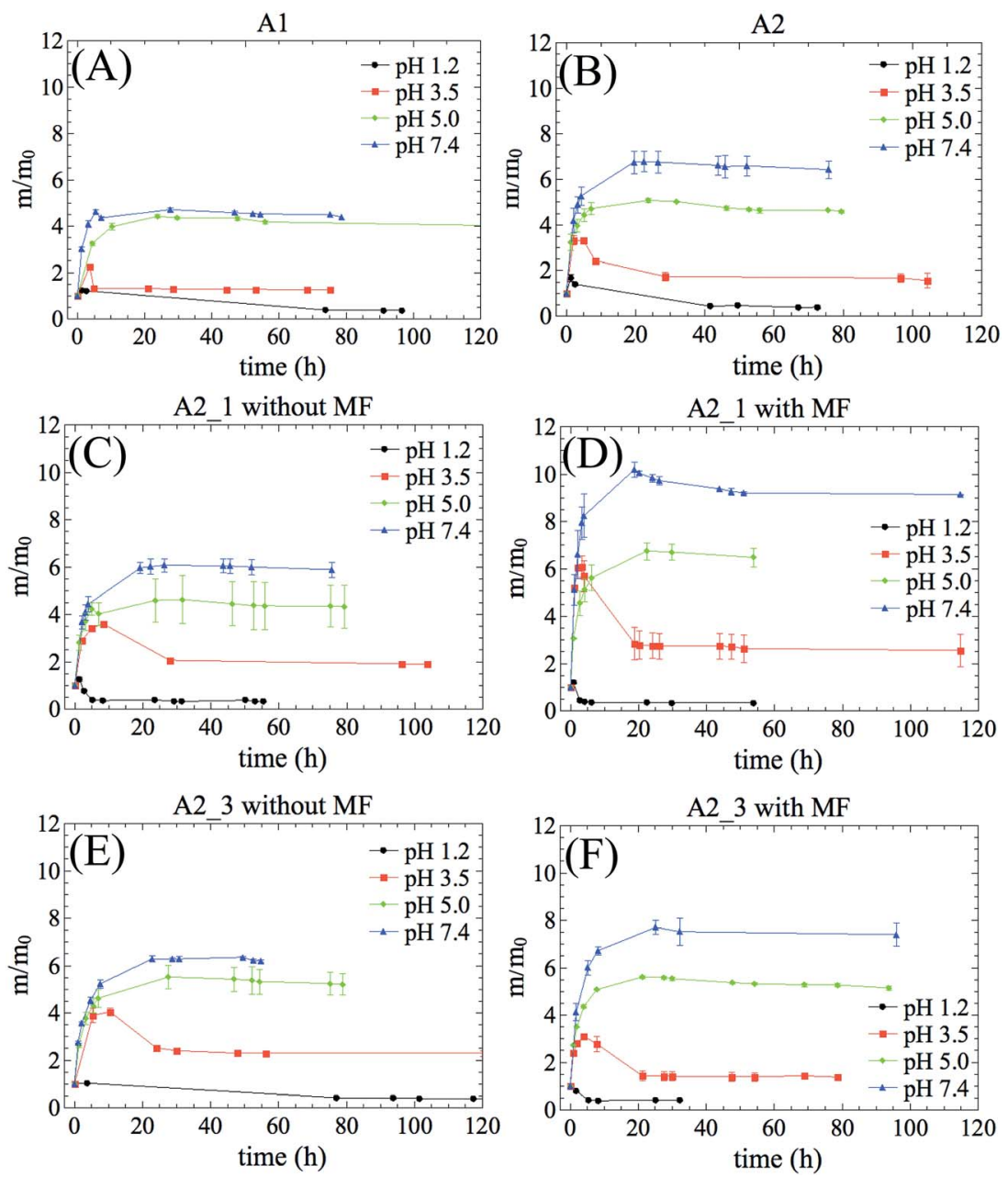

Fig. 4 Time-dependent swelling curves at the indicated $\mathrm{pH}$ at temperature of $36.5^{\circ} \mathrm{C}$ : (A) A1 without MF, (B) A2 without MF, (C) A2_1 without MF, (D) A2_1 with MF, (E) A2_3 without MF, and (F) A2_3 with MF.

volume of iron rich samples decreased faster than the samples with less iron (Fig. 4F and S2D $†$ ). In this case, the presence of IONPs made the solvent permeation through the hydrogel networks more difficult.

For hydrogels richer in acrylate groups (A2_1, and A2_3) showed changes in their swelling profile in response to MF. At $\mathrm{pH}>\mathrm{p} K_{\mathrm{a}}$, both A2_1 and A2_3 (Fig. 4D and F) showed swelling ratios higher than that of A2 (Fig. 4B). In a most elementary form, when MF is on, the hydrogels with larger amount of acrylate groups showed more important changes in their swelling profile, as a result of larger amount of absorbed water. This suggests a synergistic effect between the acrylate groups and the iron oxide particles when exposed to MF. In the case of hydrogels with less ionizable groups in their structure, such as, A1_1 and A1_3, MF was unable to cause any changes in their swelling performance. In the hydrogels of low water absorption efficiency, the influence of magnetic field on their swelling potential is insignificant (see ESI†े). The MF sensitivity of the hydrogel increases with the increase of the amount of absorbed water.

\subsection{Cytotoxicity studies}

The cell viability essays were performed to provide valuable insights into pharmaceutical potential of the hydrogels (Fig. 5). The dot lines indicate the $\mathrm{CC}_{50}$ level, when the cell viability reaches $50 \%$. In this work, the cytotoxicity was evaluated by using VERO, fibroblasts, and macrophages cells. Various concentrations of the hydrogels, ranging from 0 to $1000 \mu \mathrm{g}$ $\mathrm{mL}^{-1}$, were exposed to the cells for $72 \mathrm{~h}$.

None of the hydrogels significantly decreased the cell viability, even in the highest concentration studied, indicating that the proposed materials are biocompatible and are suitable for use in biological environments.

If compared to A1, A1_1, and A1_3, the A2 hydrogel and its derivative (A2 containing iron oxide) showed a better cell viability, especially, by neutral red assays. Furthermore, they have shown cell viability higher than $80 \%$ for VERO and fibroblasts cells, independently of determination method (MTT or neutral red). Since the fibroblast (HT-29) cell line is used as an in vitro model to study the absorption, the transport, and the secretion by intestinal cells, these results demonstrated that the A2 hydrogels has a great pharmacological potential. 

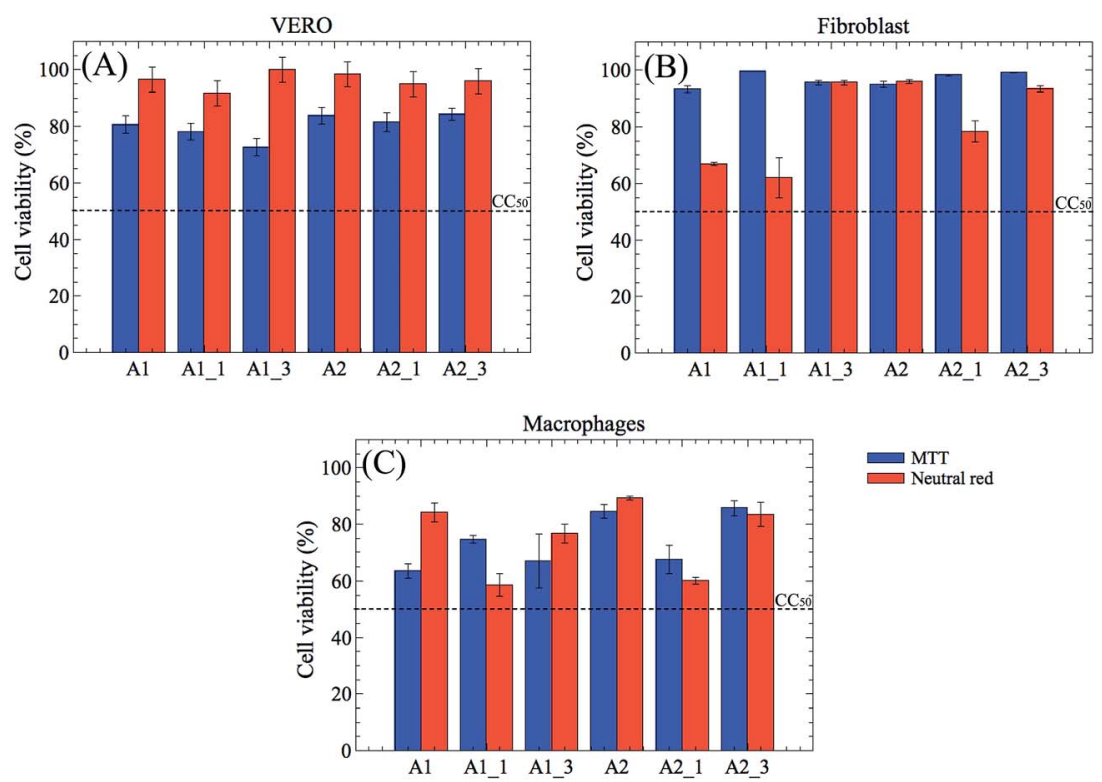

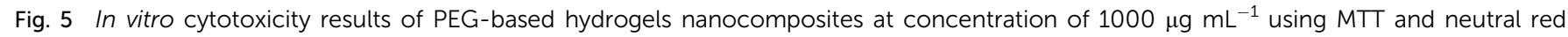
approaches. Data presented are the mean \pm SD $(n=3)$.

\subsection{Drug release}

Fig. 6 shows the time-dependent fractional release curves of prednisolone from the hydrogel nanocomposites. In this study, the A2 and A2_1 samples were chosen according to the previous results of cytotoxicity assays and swelling. For example, if compared with A1 and its derivatives, both A2 and A2_1 hydrogels have low cytotoxicity. Moreover, A2_1 showed an interesting magnetic-responsive swelling profile. Thus, for prednisolone release, the hydrogel without magnetic particle was used as reference and the hydrogel nanocomposite was analyzed under magnetic field.

In this work, $t_{50}$ and $t_{90}$ were defined as the time in which $50 \%$ and $90 \%$ of prednisolone was released, respectively. Although the A2 hydrogel showed outwardly different swelling behaviors at $\mathrm{pH} 1.2$ and 7.4, the release of prednisolone was not significantly affected by $\mathrm{pH}$ (Fig. 6A and B). Since $t_{50}$ and $t_{90}$
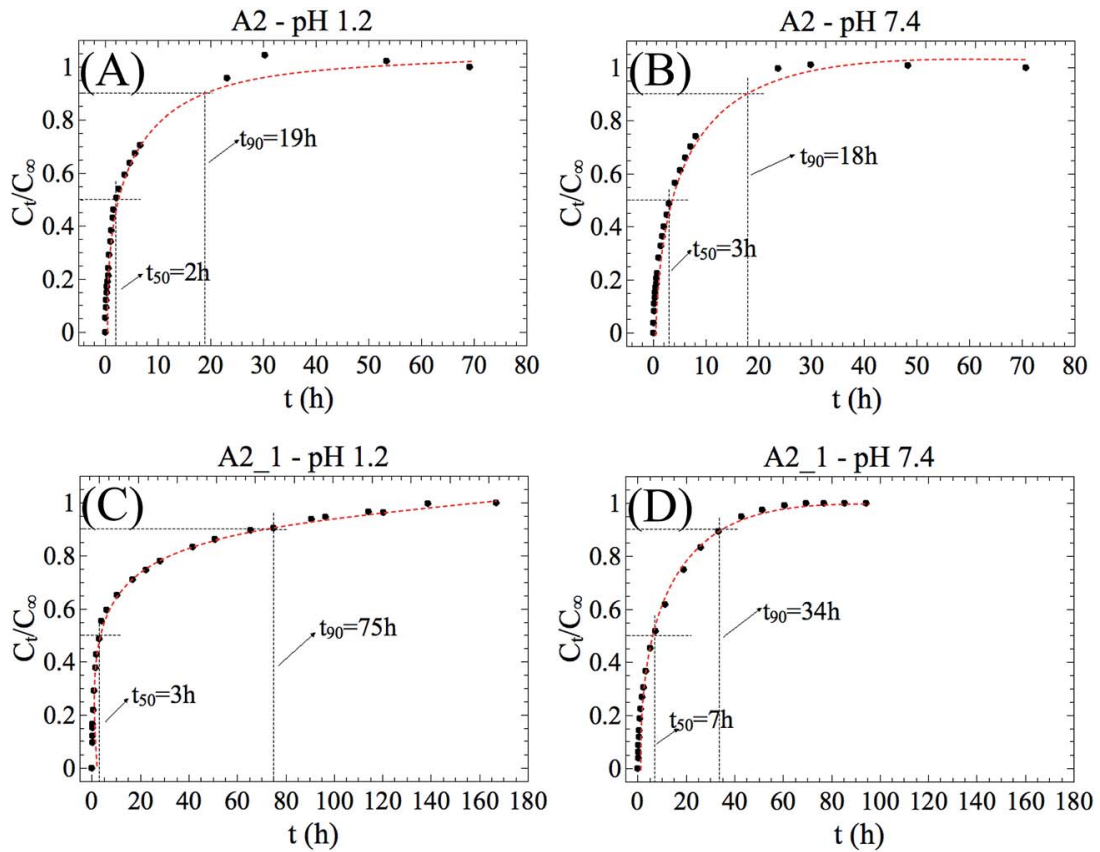

Fig. 6 Time-dependent release curves of prednisolone from A2 (reference), and A2_1 hydrogels nanocomposites in different pH at a temperature of $37{ }^{\circ} \mathrm{C}$. For the A2_1 hydrogel, the experiments were carried out using an applied magnetic field of $48 \mathrm{MGOe.}$ 
were almost the same, it can be assumed that the release ratio of prednisolone remained constant. On the other hand, the A2_1 hydrogels showed prominent prednisolone release changes in response to MF (Fig. 6C and D). $t_{90}$ increased from $19 \mathrm{~h}$ to $75 \mathrm{~h}$ at $\mathrm{pH} 1.2$ and from $18 \mathrm{~h}$ to $34 \mathrm{~h}$ at $\mathrm{pH}$ 7.4. This finding motived us to think these hydrogels are applicable to MF-triggered release of prednisolone, although further studies other than in vitro release into such applications are still needed.

The experimental data were also adjusted by applying the more general version of the power law equation, described in eqn (1). This is the most comprehensive mathematical model used to determine the release performance of drug from a polymer matrix: ${ }^{26,27}$

$$
\frac{C_{t}}{C_{\infty}}=k t^{n}
$$

where $C_{t}$ and $C_{\infty}$ are the cumulative concentrations of solute released from the hydrogel at a specified time and at equilibrium, respectively, $k$ is a constant and $n$ is a parameter used to interpret the release mechanism. Furthermore, the conceptual meanings of $n$ is dependent of the sample shape (i.e. cylinder, thin film, and sphere) as summarized in Table 2.

The values of $n$ and $k$ were obtained from slopes of the logarithmical curves of $C_{t} / C_{\infty}$ as a function of time for the hydrogels A2 and A2_1 (Table 3). It is important to mention that the eqn (1) is restricted to the first $60 \%$ of the released drug (linear part). ${ }^{29}$ The hydrogels used in the release experiments had cylindrical shapes.

Independently of $\mathrm{pH}$, the $\mathrm{A} 2$ and A2_1 hydrogels release is controlled by anomalous transport mechanism. However, with addition of magnetic particles to hydrogel, the anomalous

Table 2 Values of diffusional exponent $(n)$ for the hydrogel matrix with different shapes ${ }^{28}$

\begin{tabular}{llll}
\hline \multicolumn{2}{l}{ Diffusional exponent $(n)$} & & \\
\cline { 1 - 2 } Thin film & Cylinder & Sphere & $\begin{array}{l}\text { Transport } \\
\text { mechanism }\end{array}$ \\
\hline 0.50 & 0.45 & 0.43 & Fickian diffusion \\
$0.50<n$ & $0.45<n$ & $0.43<n$ & Anomalous \\
$<1.00$ & $<0.89$ & $<0.85$ & transport \\
1.00 & 0.89 & 0.85 & Macromolecular \\
& & & relaxation
\end{tabular}

Table 3 Fitting parameters ( $n$ and $k$ ) of eqn (1) to experimental release data of prednisolone from the A2 and A2_1 hydrogels at pH 1.2 and 7.4 with an applied magnetic field ${ }^{a}$

\begin{tabular}{llll}
\hline Sample name & & $n$ & $k$ \\
\hline A2* & pH 1.2 & $0.73 \pm 0.01$ & $0.332 \pm 0.003$ \\
& pH 7.4 & $0.66 \pm 0.02$ & $0.253 \pm 0.005$ \\
A2_ $1 * *$ & pH 1.2 & $0.49 \pm 0.02$ & $0.303 \pm 0.005$ \\
& pH 7.4 & $0.58 \pm 0.02$ & $0.185 \pm 0.002$ \\
$a *$ without MF; **under MF. & &
\end{tabular}

mechanism trended to the Fickian diffusion. This variation in $n$ is result of tortuosity effect which became more evident under MF.

The parameter $k$ is a constant characteristic of the hydrogel and may be correlated with the diffusion coefficient $(D) .{ }^{30}$ Moreover, $k$ may be correlated to $t_{50}$ since the eqn (1) is restricted to the first $60 \%$ of the released drug. Comparing A2 with $\mathrm{A} 2 \_1$, at $\mathrm{pH} 1.2$, the values of $k$ remained almost unchanged, which is related to similarity between the values of $t_{50}$ for both samples. On the other hand, the magnetic field has played an important role in reduction of $k$ such as that at $\mathrm{pH}$ 7.4. For example, when the $\mathrm{pH}$ was changed from 1.2 to 7.4 the $k$ value of A2_1 hydrogel reduced from $0.303 \pm 0.005$ to $0.185 \pm$ 0.002 . The decrease in the parameter $k$ (which is proportional to a decrease in $D$ ) is related to an increase in $t_{50}$ (Fig. 6C and D). An important insight from this study is the finding that the magnetic particles inside the hydrogel affects the prednisolone release by changing the releasing mechanism and this information could be used to control the levels of released drug. In other words, the addition of magnetic particles to hydrogels leads to a release retardant effect and the release is prolonged for longer times. The influence in the release rate was attributed to tortuosity effect, which is the result of the distribution of particles inside the polymer network. In practical terms, the particles form cutting and tortuous pathways at the hydrogel interior that makes the drug release more sustainable.

\section{Conclusions}

The hydrogel nanocomposite was prepared using vinylated PEG together with DMAAm, acrylic acid, and iron oxide nanoparticles via an ultrasound-assisted radical cross-linking/ polymerization reaction. The hydrogels were shown to be sensitive to both $\mathrm{pH}$ and magnetic field. The prednisolone released from hydrogel without magnetic particles was driven by an anomalous transport, which is defined as the sum of the contributions from macromolecular relaxation and Fickian diffusion. For hydrogels containing iron oxide, the release tended towards the Fickian transport, minimizing the influence of the macromolecular relaxation. The in vitro cytotoxicity results indicated that the obtained hydrogels are biologically relevant and have a great pharmacological potential as drug carriers in biological environments.

\section{Acknowledgements}

The authors acknowledge the funding through Coordenação de Aperfeiçoamento Pessoal de Nível Superior (CAPES) - Brazil and Conselho Nacional de Desenvolvimento Científico e Tecnológico (CNPq) - Brazil for the fellowships No. 152109/2016-1, No. 402729/2015-3 and 101157/2016-9.

\section{References}

1 T. Miyata, Polym. J., 2010, 42, 277-289.

2 J. M. Knipe and N. A. Peppas, Regener. Biomater., 2014, 1, 5765. 
3 F. M. van der Valk, D. F. van Wijk, M. E. Lobatto, H. J. Verberne, G. Storm, M. C. M. Willems, D. A. Legemate, A. J. Nederveen, C. Calcago, V. Mani, S. Ramachandran, M. P. M. Paridaans, M. J. Otten, G. M. Dallinga-Thie, Z. A. Fayad, M. Nieuwdorp, D. M. Schulte, J. M. Metselaar, W. J. M. Mulder and E. S. Stroes, Nanomedicine, 2015, 11, 1039-1046.

4 H. S. Park, J. Y. Lee, S. H. Cho, H. J. Baek and S. J. Lee, Arch. Pharmacal Res., 2002, 25, 964-968.

5 V. Prosapio, I. De Marco and E. Reverchon, Chem. Eng. J., 2016, 292, 264-275.

6 M. K. Lima-Tenório, E. T. Tenório-Neto, F. P. Garcia, C. V. Nakamura, M. R. Guilherme, E. C. Muniz, E. A. G. Pineda and A. F. Rubira, J. Mol. Liq., 2015, 210, 100-105.

7 T. Bal, B. Kepsutlu and S. Kizilel, J. Biomed. Mater. Res., Part A, 2014, 102, 487-495.

8 A. Alexander, Ajazuddin, J. Khan, S. Saraf and S. Saraf, J. Controlled Release, 2013, 172, 715-729.

9 E. M. Ahmed, J. Adv. Res., 2015, 6, 105-121.

10 P. Papaphilippou, M. Christodoulou, O.-M. Marinica, A. Taculescu, L. Vekas, K. Chrissafis and T. KrasiaChristoforou, ACS Appl. Mater. Interfaces, 2012, 4, 2139-2147.

11 L. Peng, T. Liu, S. Liu, Y. Han, X. Li, N. Guang and W. Sheng, J. Polym. Res., 2015, 22, 1-12.

12 E. T. Tenorio-Neto, M. R. Guilherme, M. K. Lima-Tenorio, D. B. Scariot, C. V. Nakamura, A. F. Rubira and M. H. Kunita, Colloid Polym. Sci., 2015, 293, 3611-3622.

13 A. V. Reis, A. R. Fajardo, I. T. A. Schuquel, M. R. Guilherme, G. J. Vidotti, A. F. Rubira and E. C. Muniz, J. Org. Chem., 2009, 74, 3750-3757.

14 M. K. Lima-Tenorio, E. T. Tenorio-Neto, M. R. Guilherme, F. P. Garcia, C. V. Nakamura, E. A. G. Pineda and A. F. Rubira, Chem. Eng. J., 2015, 259, 620-629.

15 F. J. C. Bayard, W. Thielemans, D. I. Pritchard, S. W. Paine, S. S. Young, P. Bäckman, P. Ewing and C. Bosquillon, J. Controlled Release, 2013, 171, 234-240.
16 M. H. Kunita, M. R. Guilherme, L. C. Filho, E. C. Muniz, E. Franceschi, C. Dariva and A. F. Rubira, J. Colloid Interface Sci., 2011, 361, 331-337.

17 D. Contreras-López, E. Saldívar-Guerra and G. LunaBárcenas, Eur. Polym. J., 2013, 49, 1760-1772.

18 Z. Chen, M. Zhao, K. Liu, Y. Wan, X. Li and G. Feng, J. Mater. Sci.: Mater. Med., 2014, 25, 1903-1913.

19 A. Akın and N. Işıklan, Int. J. Biol. Macromol., 2016, 82, 530540.

20 E. A. Morales-Wiemer, J. Macossay and E. Bucio, Radiat. Phys. Chem., 2013, 84, 166-169.

21 R. M. Silverstein, F. X. Webster, D. J. Kiemle and D. L. Bryce, Spectrometric Identification of Organic Compounds, Wiley, 2014.

22 E. T. Tenório-Neto, A. Baraket, D. Kabbaj, N. Zine, A. Errachid, H. Fessi, M. H. Kunita and A. Elaissari, Mater. Sci. Eng., C, 2016, 61, 688-694.

23 M. Wiśniewska, T. Urban, E. Grządka, V. I. Zarko and V. M. Gun'ko, Colloid Polym. Sci., 2014, 292, 699-705.

24 H. Hezaveh and I. I. Muhamad, Carbohydr. Polym., 2012, 89, 138-145.

25 S.-H. Hu, T.-Y. Liu, D.-M. Liu and S.-Y. Chen, Macromolecules, 2007, 40, 6786-6788.

26 R. W. Korsmeyer, R. Gurny, E. Doelker, P. Buri and N. A. Peppas, Int. J. Pharm., 1983, 15, 25-35.

27 P. L. Ritger and N. A. Peppas, J. Controlled Release, 1987, 5, 23-36.

28 E. T. Tenorio-Neto, E. L. Silva, T. S. P. Cellet, E. P. Silva, E. Franceschi, L. C. Filho, A. F. Rubira and M. H. Kunita, J. Braz. Chem. Soc., 2013, 24, 327-335.

29 E. P. da Silva, D. L. A. Sitta, V. H. Fragal, T. S. P. Cellet, M. R. Mauricio, F. P. Garcia, C. V. Nakamura, M. R. Guilherme, A. F. Rubira and M. H. Kunita, Int. J. Biol. Macromol., 2014, 67, 43-52.

30 Y. Fu and W. J. Kao, Expert Opin. Drug Delivery, 2010, 7, 429444. 